Nature Geoscience

August 2016, Volume 9 Issue 8 Pages 619-+

http://dx.doi.org/10.1038/NGEO2759

http://archimer.ifremer.fr/doc/00345/45603/

(C) 2016 Macmillan Publishers Limited. All rights reserved

\title{
Extreme mantle uplift and exhumation along a transpressive transform fault
}

\author{
Maia Marcia ${ }^{1,{ }^{*}}$, Sichel Susanna ${ }^{2}$, Briais Anne ${ }^{3}$, Brunelli Daniele ${ }^{4,5}$, Ligi Marco ${ }^{5}$, Ferreira Nicolas ${ }^{1}$, \\ Campos Thomas ${ }^{6}$, Mougel Berengere ${ }^{1,7}$, Brehme Isa ${ }^{2}$, Hemond Christophe ${ }^{1}$, Motoki Akihisa ${ }^{8}$, \\ Moura Denise ${ }^{9}$, Scalabrin Carla ${ }^{10}$, Pessanha Ivo ${ }^{11}$, Alves Eliane ${ }^{2}$, Ayres Arthur ${ }^{2}$, Oliveira Pedro ${ }^{2}$
}

${ }^{1}$ Univ Bretagne Occidentale, CNRS, IUEM, Lab Domaines Ocean, Rue Dumont dUrville, F-29280 Plouzane, France.

${ }^{2}$ Univ Fed Fluminense, LAGEMAR, Ave Gal Milton Tavares Souza S-N, BR-24210340 Niteroi, RJ, Brazil.

${ }^{3}$ Univ Toulouse, GET, Ave Edouard Belin, F-31400 Toulouse, France.

${ }^{4}$ Univ Modena \& Reggio Emilia, Dipartimento Sci Chim \& Geol, Via Campi 103, I-41125 Modena, Italy.

${ }^{5}$ CNR, Geol Marina, ISMAR, Via Gobetti 101, I-40129 Bologna, Italy.

${ }^{6}$ Univ Fed Rio Grande do Norte, Dept Geol, Cidade Univ Lagoa Nova,CP 1639, BR-59072700 Natal, RN, Brazil.

7 Inst Phys Globe Paris, 1 Rue Jussieu, F-75005 Paris, France.

${ }^{8}$ Univ Estado Rio de Janeiro, Ctr Tecnol \& Ciencias, Inst Geociencias, Rua Sao Francisco, BR20550013 Rio De Janeiro, Brazil.

${ }^{9}$ Univ Sao Paulo, Inst Astron Geofis \& Ciencias Atmosfer, Rua Matao 1226,Cidade Univ, BR-05508090 Sao Paulo, Brazil.

${ }_{10}^{10}$ IFREMER, Lab Acoust, Technopole Iroise, F-29280 Plouzane, France.

${ }^{11}$ Brazilian Geol Survey, CPRM, Ave Pasteur 404, BR-22290255 Rio De Janeiro, Brazil.

* Corresponding author : Maia Marcia, email address : marcia.maia@univ-brest.fr

\begin{abstract}
:
Mantle exhumation at slow-spreading ridges is favoured by extensional tectonics through low-angle detachment faults1, 2, 3, 4, and, along transforms, by transtension due to changes in ridge/transform geometry5, 6. Less common, exhumation by compressive stresses has been proposed for the large-offset transforms of the equatorial Atlantic7, 8. Here we show, using high-resolution bathymetry, seismic and gravity data, that the northern transform fault of the St Paul system has been controlled by compressive deformation since $\sim 10$ million years ago. The long-lived transpression resulted from ridge overlap due to the propagation of the northern Mid-Atlantic Ridge segment into the transform domain, which induced the migration and segmentation of the transform fault creating restraining stepovers. An anticlockwise change in plate motion at $\sim 11$ million years ago5 initially favoured extension in the left-stepping transform, triggering the formation of a transverse ridge, later uplifted through transpression, forming the St Peter and St Paul islets. Enhanced melt supply at the ridge axis due to the nearby Sierra Leone thermo chemical anomaly9 is responsible for the robust response of the northern Mid-Atlantic Ridge segment to the kinematic change. The long-lived process at the origin of the compressive stresses is directly linked to the nature of the underlying mantle and not to a change in the far-field stress regime.
\end{abstract}


49 When Darwin stopped in the St. Peter \& St. Paul's islets in 1832, he recognised that the

50 rocks exposed there were not volcanic and postulated that the mechanism for their

51 formation was different from that building other oceanic islands ${ }^{10}$. The islets, formed by

52 variably serpentinised and mylonitised peridotites ${ }^{11,12}$, are currently uplifting at rates of

$531.5 \mathrm{~mm} / \mathrm{yr}^{12}$. Previous work suggested that the exposure of such large volume of

54 ultramafic rocks resulted from an abnormally cold upper mantle $\mathrm{e}^{13-15}$ or cold

55 lithosphere ${ }^{16}$ in the Equatorial Atlantic and that the islets were either part of an

56 extensional flexural ridge, as observed in other transform faults ${ }^{6,13}$ or linked to

57 compression ${ }^{8}$. Our data reveal that the islets are part of a major uplift of the lithospheric

58 mantle due to a 10 Myr long period of transpression at the transform boundary ${ }^{17}$.

59 Similar push-ups exist along continental strike-slip faults ${ }^{18,19}$ but this is the first time

60 one has been fully mapped in the oceanic lithosphere near a present-day spreading

61 centre. Understanding the processes responsible for its formation will shed new light on

62 the behaviour of large transform boundaries and their response to changes in both local

63 and far-field stresses as well as on mechanisms leading to mantle exhumation at 64 spreading centres. 
Four transform faults and three intra-transform ridge segments, cumulating a $630 \mathrm{~km}$ offset, form the complex St. Paul transform system (Fig. 1 \& Supplementary Fig. S1). Tectonic patterns and lithology reveal that the St. Peter \& Paul's islets are part of a major, $200 \mathrm{~km}$-long, $30 \mathrm{~km}$-wide submarine shear zone that accommodates transpressive stresses along the northern transform fault of the St. Paul system ${ }^{17}$ (Fig. 1). Most dredged samples are breccias of mylonitic peridotite and ultramylonites that underwent various degrees of serpentinisation and deformation (Supplementary Fig. S2). The morphology and the distribution of the deformation in the transform fault allow three tectonic domains in the shear zone to be defined: the Western Transfer Zone (WTZ), the Central Transpressive Zone (CTZ) and the Eastern Shear Zone (ESZ) (Fig. 2).

An important segmentation of the transform fault with associated push-up ridges resulting from dextral transpression characterizes the WTZ (Fig. 2a). Eastwards, a series of left-stepping restraining bends and offsets in the transform, associated with a large topography, form the distinct tectonic pattern of the CTZ. Thrust faults (Figs. 1, 2b \& 3) mark the base of its south flank, overlapping the crust formed at the north intratransform segment. These thrust faults, imaged by seismic reflection data (Fig. 3), are associated with the exposure of mylonitised peridotites and deformed sediments at this crustal contact. They form positive flower structures resulting from transpression at the restraining offsets along the shear zone (Fig. 2b). The area is seismically very active and, while most of the events have strike-slip focal mechanisms, a few compressive events ${ }^{20}$ near the islets confirm the presence of thrust faults. The $\sim 3500$ m-high Atobá Ridge,

88 located at the largest offset of the transform fault, is a major push-up ridge in the centre of the wider transpressive feature, marking the location of the most intense deformation ${ }^{21}$. The gravity-derived density structure over this portion of the shear zone 
and the nature of the rocks sampled on both the islets and the flanks of the Atobá ridge (Fig. 4 and Supplementary Figs. S2 \& S3) imply the presence of a core of uplifted, relatively unaltered high-density mantle beneath the islets and an anomalously thick low density layer on the ridge flanks, especially the southern one. We suggest that the thickening of the low-density layer derives from a local deepening of the serpentinisation front. Accordingly, the $500^{\circ} \mathrm{C}$ isotherm, that can be considered the limit of the serpentinisation process ${ }^{22}$, lies at a depth of $25 \mathrm{~km}$ below the Atobá ridge (Fig. 4) i.e. deeper than the inferred maximum depths of the low-density layer, supporting the idea that the low-density material is related to hydration of mantle rocks. In the ESZ (Fig. 2c), the transform fault crosses a deep basin similar to the transform fault basins observed elsewhere in the St. Paul system (Fig. 1 and Supplementary Fig. S1). The basin morphology suggests the absence of significant transpression in this section of the shear zone. Close to the intra-transform segment, the transform becomes a double fault. This reveals that even in the more linear part of the transform domain the motion is not purely strike-slip.

The oblique segments and the offsets disrupting the main trend of the western transform boundary developed after several episodes of southward propagation of the northeastern segment of the Mid-Atlantic Ridge (MAR) in the last $10 \mathrm{Myr}$, as revealed by the lengthening of its abyssal hills. The absence of asymmetric faulting at this largeoffset ridge-transform intersection implies that the robust segment receives enough melt supply to counteract the cold-edge effect of the transform fault ${ }^{23}$ (Figs. $1 \& 2 \mathrm{a}$ ). The short northern intra-transform segment, although comparatively less robust, did not retreat to accommodate the propagation of the MAR segment, leading to an overlap of both spreading segments. The morphology of the intra-transform segment, with sub- 
116 parallel abyssal hills mapped on both flanks, and the basalt samples recovered on and

117 off axis are consistent with spreading dominated by volcanic processes for at least the

118 last 10 Myr. However, contrary to the MAR, this small segment did not increase in

119 length, reflecting the difference in melt supply between the segments.

121 The change in the tectonics of the northern boundary of the St. Paul system started $\sim 11$

$122 \mathrm{Ma}$, when a $5^{\circ}$ counterclockwise change in the spreading direction between the South

123 America and Nubia plates occurred, inducing extension at large-offset left-stepping 124 transforms in the Central and Equatorial Atlantic ${ }^{5,24}$. The origin of the St. Paul 125 transpressive shear zone relates to the way the spreading geometry locally adjusted to 126 this plate motion change. We construct an evolutionary scenario describing the 127 responses of the transform to a sequence of far and local stress changes (Fig. 5). The 11 128 Ma counterclockwise rotation locally resulted in the transtensional formation of a 129 flexural transverse ridge along the northern border of the transform fault. This same 130 event resulted in the synchronous growth of the Vema transverse ridge at $11^{\circ} \mathrm{N}^{5}$. 131 Shortly after, the spreading ridge segments started to adjust to the new spreading 132 geometry, with the lengthening of the MAR segment, while the intra-transform segment 133 to the East remained roughly stable. As the MAR segment kept propagating south, the 134 western part of the transform started to segment and this non-uniform adjustment 135 resulted in the formation of restraining bends and offsets, inducing localized 136 transpression on the western portion of the flexural transverse ridge. The resulting 137 structure is bounded by low-angle thrusting along the external faults of the system (Fig. 138 2). The four lengthening events, marked by the steps in the transform boundary, 139 correspond to progressively slower propagation rates, as the ridge geometry adjusted to 140 the local stresses (Fig. 5). The oldest and largest offset corresponds to a fast 
141 displacement of the western transform segment from its main trend. This event created 142 the first compressive stresses at the transverse ridge. As the transform fault adjusted

143 southwards during the second event, the increase in the fault segment offset induced 144 higher stresses that begun to form the sigmoidal push-up Atobá ridge. The following 145 episode, of smaller amplitude, formed a smaller restraining bend, continuing to sustain 146 the uplift of the Atobá ridge and forming the southern part of the CTZ. The most recent 147 evolution also displays southward deviations of the shear zone resulting in 148 transpressive deformation in the WTZ. The morphology, focal mechanisms, and 149 evidence for uplift in the Atobá Ridge show that transpression is still active in the western part of the shear zone. Such an active deformation implies that the plate 151 boundary did not reach a steady-state geometry and that the changes in the spreading 152 geometry are still being accommodated, although at relatively lower present-day rates. 153 Despite their similar offset, the Vema and the northern St. Paul transform show a 154 different sequence of adjustments both starting with the same kinematic change. The 155 Vema transform reacted with a single short transtensive adjustment while St. Paul 156 records a multiple set of events over a larger time-span. A plausible cause of this 157 different behaviour is the influence of the Sierra Leone hotspot, which may have 158 enhanced the magma supply of the MAR segment just north of St Paul transform ${ }^{9}$. 159 Lengthening of ridge segments due to increased magma supply is well documented 160 along the MAR $^{25}$ and may be an important mechanism here. Geochemical data ${ }^{9,14,26}$ show 161 the existence of a mantle composition boundary within the St. Paul system, with an 162 enriched mantle beneath the MAR segment north of the system extending to the 163 northern intra-transform segment. The volcanic morphology of these segments possibly 164 reflects the nature of the mantle, which favours enhanced melting. 
166 Continental shear zones where restraining step-overs result in transpressive flower-like

167 structures and push-up ridges, exposing mylonites and ultra-mylonites at the surface

168 are well documented ${ }^{18,19}$. The observed structural and petrologic patterns at the St Paul 169 northern transform boundary are similar, with multi-segmented and sub-parallel faults 170 away from the step-ups and oblique faults close to them. Associated thrust faults uplift 171 large reliefs and expose deep rocks distributed along bands parallel to the main strike172 slip fault zone, forming positive flower structures. At the centre of these features, the 173 higher topography is associated with a push-up block, oblique faults and intense 174 deformation ${ }^{18,21}$. The MAR half-spreading rate $(16 \mathrm{~mm} / \mathrm{yr})^{27}$ yields convergence rates of $17532 \mathrm{~mm} / \mathrm{yr}$ at the step-overs and transpressive segments of the fault. This amount of 176 shortening is sufficient to uplift a $100 \mathrm{~km}$-long block by more than $3500 \mathrm{~m}$, with 177 present-day uplift rates of $1.5 \mathrm{~mm} / \mathrm{yr}^{12}$, comparable to those estimated for structures 178 observed along continental strike-slip faults ${ }^{18,19}$.

180 The evolution of the northern St. Paul plate boundary, where the southward migration 181 of both the MAR segment and the transform fault is progressively accommodated 182 through bends, offsets and oblique structures over a wide shear zone, lead to a 183 particular situation in the mid-ocean ridge system, with long-lived regional-scale 184 transpression along the transform. Whereas most exposed mantle rocks near mid185 ocean ridges result from extensional tectonics along detachment faults, our study 186 reveals that the peridotites and mylonites of the St. Peter \& Paul's islets result from a 187 major uplift of the oceanic lithosphere along a transpressive shear zone due to local 188 stresses which have been active during a time much longer than usually necessary for a 189 plate boundary to adjust to a kinematic change. This may also be the case along other 190 major transform faults, although probably at a smaller scale. Here we show that even 
191 large-offset transforms, materializing large contrasts in lithosphere thickness, may 192 deform due to the local stresses induced by the increase in melt supply at the spreading 193 ridge. Mantle composition and temperature may therefore trigger the local response of 194 the lithosphere. To understand deformation at large transforms, mantle processes must 195 not be neglected.

\section{References}

198 1. Dick, H. J. B., Lin, J. \& Schouten, H. An ultra slow spreading class of ocean ridge. Nature 199 426, 405-412 (2003).

200 2. Sauter, D. et al. Continuous exhumation of mantle-derived rocks at the Southwest 201 Indian Ridge for 11 million years. Nature Geoscience 6, 314-320 (2013)

202 3. Escartín, J. et al. Central role of detachment faults in accretion of slow-spreading 203 oceanic lithosphere. Nature 455, 790-794 (2008).

204 4. Smith, D. K., Escartin, J., Schouten, H. \& Cann, J. R. Fault rotation and core complex 205 formation: significant processes in seafloor formation at slow-spreading midocean 206 ridges (Mid-Atlantic Ridge, 13-15²N). Geochem. Geophys. Geosyst. 9, Q03003, 207 doi:10.1029/2007GC001699 (2008).

208 5. Bonatti, E. et al. Flexural uplift of a lithospheric slab near the Vema transform (Central 209 Atlantic): Timing and mechanisms. Earth Planet. Sci. Lett. 240, 642-655 (2005).

210 6. Tucholke, B. E. \& Schouten, H. Kane Fracture Zone. Mar. Geophys. Res. 10, 1-39 (1988)

211 7. Bonatti, E. et al. Transform migration and vertical tectonics at the Romanche fracture 212 zone, Equatorial Atlantic. J. Geophys. Res. 99, 21779 -21802 (1994).

213 8. Palmiotto, C. et al. Nonvolcanic tectonic islands in ancient and modern oceans, 214 Geochem. Geophys. Geosyst. 14, 4698-4717 (2013). 
216 Sierra Leone mantle plume on the equatorial Mid-Atlantic Ridge: A Nd-Sr-Pb isotopic 217 study. J. Geophys. Res. 99, 12,005-12,028 (1994).

218 10. Darwin, C. Geological Observations on the Volcanic Islands and Parts of South 219 America Visited During the Voyage of H.M.S. 'Beagle', 3 ${ }^{\text {rd }}$ ed. (Smith, Elder, London, 220 1891).

221 11. Melson, W.G., Jarosewich, E., Bowen, V.T., Thompson, G. St. Peter and St. Paul Rocks: a 222 high-temperature, mantle-derived intrusion. Science 155, 1532-1535 (1967).

223 12. Campos, T. F. C., Bezerra, F. H. R., Srivastava, N. K., Vieira, M. M. and Vita-Finzi, C. 224 Holocene tectonic uplift of the St Peter and St Paul Rocks (Equatorial Atlantic) consistent 225 with emplacement by extrusion. Marine Geology 271, 177-186 (2010).

226 13. Hekinian, R. et al. Submersible observations of Equatorial Atlantic mantle: the St Paul 227 Fracture Zone region. Mar. Geophys. Res. 21, 529-560 (2000).

228 14. Schilling, J.G. et al. Thermal structure of the mantle beneath the equatorial Mid229 Atlantic Ridge: inference from the spatial variation of dredged basalt glass compositions. 230 J. Geophys. Res. 100, 10057-10076 (1995).

231 15. Bonatti, E. Anomalous opening of the equatorial Atlantic due to an equatorial mantle 232 thermal minimum. Earth Planet. Sci. Lett. 143, 147-160 (1996).

233 16. Brunelli, D. \& Seyler, M. Asthenospheric percolation of alkaline melts beneath the St. 234 Paul region (Central Atlantic Ocean). Earth Planet. Sci. Lett. 289, 393-405 (2010).

235 17. Maia, M. et al. Complex ridge-transform evolution and mantle exhumation at the St. 236 Paul fracture zone system, Equatorial Atlantic. Preliminary results from the COLMEIA 237 cruise. Abstract OS42A-01 presented at 2013 Fall Meeting, AGU, San Francisco, Calif., 923813 Dec (2013). 
18. Mann, P. Global catalogue, classification and tectonic origins of restraining and

240 releasing bends on active and ancient strike-slip fault systems. In Tectonics of Strike-Slip

241 Restraining and Releasing Bends 290, 239-253 (Geological Society Special Publications,

242 London, 2007)

243 19. Dair, L. \& Cooke, M. L. San Andreas fault geometry through the San Gorgonio Pass,

244 California. Geology 37, 119-122 (2009).

245 20. Wolfe, C.J., Bergman, E.A. \& Solomon, S.C. Oceanic transform earthquakes with 246 unusual mechanism or locations: relation to fault geometry and state of stress in the 247 adjacent lithosphere. J. Geophys. Res. 98, 16187-16211 (1993).

248 21. McClay, K. \& Bonora, M. Analog models of restraining stepovers in strike-slip fault 249 systems. AAPG Bulletin 85, 233-260 (2001).

250 22. Ulmer, P. \& Trommsdorff , V. Serpentine stability to mantle depths and subduction251 related magmatism. Science 268, 858-861 (1995).

252 23. Ligi, M., Bonatti, E., Cipriani, A. \& Ottolini, L. Water-rich basalts at mid-ocean ridge 253 cold spots. Nature 434, 66-69 (2004).

254 24. Ligi, M., Bonatti, E., Gasperini, L. \& Poliakov, A. N. B. Oceanic broad multifault 255 transform plate boundaries. Geology 30, 11-14 (2002).

256 25. Gente, P. et al.. Characteristics and evolution of the segmentation of the Mid-Atlantic 257 ridge between $20^{\circ} \mathrm{N}$ and $24^{\circ} \mathrm{N}$ during the last 10 million years. Earth Planet. Sci. Lett. 258 129, 55-71 (1995).

259 26. Le Voyer, M., Cottrell, E., Kelley, K. A., Brounce, M. \& Hauri, E. H. The effect of primary 260 versus secondary processes on the volatile content of MORB glasses: An example from 261 the equatorial Mid-Atlantic Ridge $\left(5^{\circ} \mathrm{N}-3^{\circ} \mathrm{S}\right)$, J. Geophys. Res. Solid Earth 120, 125-144 262 (2015). 

Int. 181, 1-80 (2010).

Acknowledgements

The COLMEIA marine expedition was funded by the French Ministry of Research through the grant to the Flotte Océanographique Française. Additional supporting grants came from CNRS-INSU program "Campagnes à la mer", Labex MER and Région Bretagne, France, and from Universidade Federal Fluminense and CPRM, Brazil. M.L. acknowledges supporting grant PRIN 20125JKANY_002. We thank SECIRM, Brazilian 273 Navy, for their help and support to this project. We are grateful to Captain G. Ferrand and his crew from research vessel L'Atalante and to the technical staff of GENAVIR for 275 their help on acquiring the data presented here.

Author contributions

M.M. and S.S. conceived the COLMEIA project. M.M. led the COLMEIA cruise. M.M, A.B. and D.B. acquired, processed and interpreted the different data sets and wrote the paper. M.L. provided complementary bathymetry data, processed and interpreted the different data sets and wrote the paper. N.F. interpreted the bathymetry data. E.A., A.A. and P.O. interpreted the seismic data for sediment thickness. D.M. built the crustal age 284 model and acquired the data during the COLMEIA cruise. T.C., B.M., I.B., C.H., A.M., C.S. 285 and I.P. acquired the data during the COLMEIA cruise. 
289 Supplementary information is available in the online version of the paper. Reprints and 290 permissions information are available online at www.nature.com/reprints.

291 Correspondence and requests for materials should be addressed to M.M., Laboratoire 292 Domaines Océaniques, CNRS-Université de Bretagne Occidentale, IUEM, Rue Dumont 293 d’Urville, 29280 Plouzané, France, marcia.maia@univ-brest.fr.

294

295 Competing financial interests

296 The authors declare no competing financial interests.

Figure captions

Figure 1. 1a. Location of the St Paul shear zone and other notable features of the

301 Equatorial Atlantic. The Sierra Leone hotspot ${ }^{9}$ location is shown by the red star. $1 \mathrm{~b}$. 302 Multibeam bathymetry of the St. Paul shear zone. A black star shows the location of the 303 St. Peter \& St. Paul's islets. The thick black lines represent the present-day active 304 transform faults, with the arrows showing the direction of plate motions. The black lines 305 with the ticks represent the thrust faults. The white lines show the present-day 306 spreading axes. The labelled rectangles show the areas detailed in Figure 2.

308 Figure 2. Shaded bathymetry of three different portions of the northern St. Paul shear 309 zone. 2a. West Transfer Zone (WTZ) displaying a multi-segmented transform fault sub310 parallel to the current spreading direction and three en-echelon push-up ridges. $2 \mathrm{~b}$. 311 Central Transpressive Zone (CTZ) displaying step-overs of the transform fault on either 312 side of the St Peter and Paul's islets. The Atobá Ridge is located at the central step. The 
313 base of the south flank of the CTZ displays a series of thrust faults. 2c. Eastern Shear

314 Zone (ESZ) where the transform fault crosses a deep basin. Fault captions as in Figure 1.

316 Figure 3. Fully migrated reflection seismic line crossing the St. Paul shear zone (a)

317 (location shown in the inset) and interpreted cartoon (b) showing the thrust faults at 318 depth associated with the mylonite exposures and the positive flower structure. The 319 sediment cover also shows intense deformation. The processing techniques are 320 described in the Methods section.

322 Figure 4 . Thickness map of a $2800 \mathrm{~kg} / \mathrm{m}^{3}$ density layer, that can correspond to crust 323 and/or to altered mantle, derived from the gravity data and superimposed on a shaded 324 high-resolution bathymetry. The density distribution is consistent with the rocks 325 sampled in the islets and on the submarine flanks of the CTZ (Supplementary Figure S2). 326 The black lines show the depth of the $500{ }^{\circ} \mathrm{C}$ isotherm contoured at a $1 \mathrm{~km}$ step. The 327 model parameters and method of calculation are described in the Methods section. The 328 black star shows the St. Peter \& Paul's islets. Fault captions as in Figure 1.

330 Figure 5. Sketch of the evolution of the St. Paul shear zone from a configuration prior to 331 the change in plate motion at $\sim 11 \mathrm{Ma}$ on the top to the present boundary geometry, on 332 the bottom. Blue areas mark extensional features, red are compressive and gray shows 333 the inactive parts of the ridge. The large arrows show the spreading directions and the 334 thin black vertical arrow show the propagation of the northern MAR segment. The thin 335 oblique arrows show the direction of the local stresses. 
339 Gravity modelling.

340 The gravity data obtained during the cruise ${ }^{28}$ were processed in the conventional way 341 (Eötvos, drift and latitude corrections) to compute the free-air anomalies before being 342 merged into a grid, together with satellite-derived free-air anomaly data ${ }^{29,30}$ to obtain 343 the free-air anomaly used in this study. The density model consists of three layers of 344 constant density: the sediment cover, the crust or altered mantle (or their density 345 proxy) and the normal mantle, respectively with densities of 2400, 2800 and 3300 $346 \mathrm{~kg} / \mathrm{m}^{3}$ and $1030 \mathrm{~kg} / \mathrm{m}^{3}$ for the water. Modelled densities do not attempt to reproduce 347 the complex reality inferred from the petrology, but consider densities that may be close 348 to altered and serpentinised peridotites, mylonites and crustal rocks. To construct a 349 sediment thickness grid, we used the values derived from the interpretation of the 350 seismic lines obtained during the cruise as well as available data from older cruises and 351 extrapolated them to the neighbouring areas. The sedimentary infill reaches 300 to 500 $352 \mathrm{~m}$ in the nearby basins, but most of the area presents only relatively thin sediment cover 353 (less than $100 \mathrm{~m}$ ). As the seismic lines are spaced further apart than the echosounder 354 sampling, the resolution of the sediment grid is not as good as the bathymetry, so for the 355 model, we interpolated the high-resolution bathymetry ${ }^{28}$ onto a $1 \mathrm{~km}$ step grid, 356 compatible with the sediment thickness grid, after projecting all data from geographic 357 degrees to UTM kilometres. From the bathymetry and the sediment thickness, we 358 calculated the basement topography. To calculate the Mantle Bouguer anomaly, we 359 assumed a constant, $6 \mathrm{~km}$-thick "crust" (or its proxy, a $2800 \mathrm{~kg} / \mathrm{m}^{3}$ density layer), using 360 the basement as the top of the layer. The gravity effect of this model was computed in 361 the Fourier domain using the multi-layer method, developed to account for both rapidly 362 varying topography and shallow water depths ${ }^{30}$ and subtracted from the free-air 
anomaly grid yielding the Mantle Bouguer anomaly. Before inverting for the layer

364 thickness variations from the assumed $6 \mathrm{~km}$ constant "crust", we removed the effect of

365 the cooling of the lithosphere. Several thermal models were tested: a simple age 366 model 31,32 and passive flow models ${ }^{33,34}$ using different values for the thermal

367 conductivity. As differences were only minor between the model results and expressed 368 mostly as a broad regional trend, we chose to keep the age model. Moreover, the passive 369 flow models tend to overemphasize the cold-edge effect, which our bathymetry data 370 suggest is not so marked here, despite the large offset. The $2800 \mathrm{~kg} / \mathrm{m}^{3}$ layer thickness 371 displayed in Figure 4 is obtained by adding the computed thickness variations to the 6 372 km thick "crust".

374 Seismic processing

375 The seismic lines were acquired with a 24 channels streamer using two air guns with 376105 and 85 cubic inches ${ }^{28}$. All lines were processed using software Sispeed v5.5 377 developed by IFREMER. Common mid-point gathers were stacked and migrated using a 378 simple velocity model with a sound velocity of $1500 \mathrm{~m} / \mathrm{s}$ assigned for both water and 379 sediments. After processing, interpretation was performed using Kingdom 8.5 software. 380 The quality of the seismic lines in this rough topography area was checked by 381 comparison between the sea bottom reflector derived from the seismic profiles and the topography derived from the high-resolution multibeam bathymetry. Only in a few

383 areas, where the seismic lines closely parallel high scarps, significant differences due to 384 lateral echoes were found. A few seismic lines crossing the CTZ were migrated with a 385 more complex model for the velocity of the sound in the sediments and the basement, accounting for the increase in the sound velocity with depth, in order to better identify 387 the reflectors in the basement. The model consists of a sediment layer with a velocity of 

of 500 m-thick layers with a velocity increase of $500 \mathrm{~m} / \mathrm{s}$ each. The last horizon, at a depth of $5800 \mathrm{~m}$ from the top of the oceanic crust, seismically separates the crust from

391 the mantle with a velocity 7500 to 8000 m/s. The line shown in Figure 3 was processed 392 with this full migration model.

394 Crustal age modelling

395 Since the proximity of the magnetic equator hinders the identification of magnetic 396 anomalies, we analysed the evolution of this part of the St. Paul system through a 397 kinematic reconstruction using the most recently published poles of rotation ${ }^{35}$. 398 Theoretical crustal ages were calculated using the present day geometry of the mid399 oceanic ridge and these poles.

Data availability

402 Gravity and seismic data were acquired during the COLMEIA cruise ${ }^{28}$. The multibeam 403 bathymetry used in this work came mainly from the COLMEIA cruise ${ }^{28}$, completed with 404 data from PRIMAR96 ${ }^{36}$ and S7 (R/V Strakhov) ${ }^{37}$ cruises. Satellite gravity data ${ }^{29}$ used to 405 complement the ship data are available at http://topex.ucsd.edu/grav_outreach/\#grid. 406 The global relief dataset $^{38}$ ETOPO1 used to draw Figure 1 is available at 407 https://www.ngdc.noaa.gov/mgg/global/global.html. The data that support the findings 408 of this study are available from the corresponding author upon request.

410 Code availability

411 The FORTRAN code used to calculate the gravity anomalies ${ }^{30}$ is available from the 412 corresponding author upon request. 
28. Maia, M. COLMEIA cruise, RV L'Atalante, http://dx.doi.org/10.17600/13010010, (2013).

29. Sandwell, D. T., Müller, R. D., Smith, W. H. F. , Garcia, E. \& Francis, R. New global marine gravity model from CryoSat-2 and Jason-1 reveals buried tectonic structure. Science 346, 65-67 (2014).

30. Maia, M. \& Arkani-Hamed, J. The support mechanism of the young Foundation Seamounts inferred from bathymetry and gravity. Geophys. J. Int. 149, 190-210 (2002). heat flow with age. J. Geophys. Res. 82, 803-827 (1977).

32. Stein, C.A. \& Stein, S. A model for the global variation in oceanic depth and heat flow with lithospheric age. Nature 359, 123-129 (1992).

33. Morgan, J.P. \& Forsyth, D.W. Three-dimensional flow and temperature perturbations due to a transform offset: Effects on oceanic crustal and upper mantle structure. $J$. Geophys. Res. 93, 2955-2966 (1988).

34. Ligi, M., Cuffaro, M., Chierici, F. \& Calafato, A. Three-dimensional passive mantle flow beneath mid-ocean ridges: An analytical approach. Geophys. J. Int. 175, 783-805 (2008). on the late Cretaceous/Tertiary plate tectonic evolution of the Caribbean. In Sedimentary Basins of the World, Caribbean Basins 4, 33-59 (Elsevier, Amsterdam, 1999)

434 36. Gasperini L. et al. New data on the geology of the Romanche F.Z., equatorial Atlantic: 435 PRIMAR-96 cruise report, Giornale di Geologia 59, 3-18 (1997).

436 37. Udintsev G.B. Equatorial Segment of the Mid-Atlantic Ridge. IOC Technical Series 46 437 (UNESCO, New York, 1996). 
438 38. Amante, C. \& Eakins, B.W. ETOP01 1 Arc-Minute Global Relief Model: Procedures,

439 Data Sources and Analysis. NOAA Technical Memorandum NESDIS NGDC-24. National 440 Geophysical Data Center, NOAA. doi:10.7289/V5C8276M (2009).

441

442 

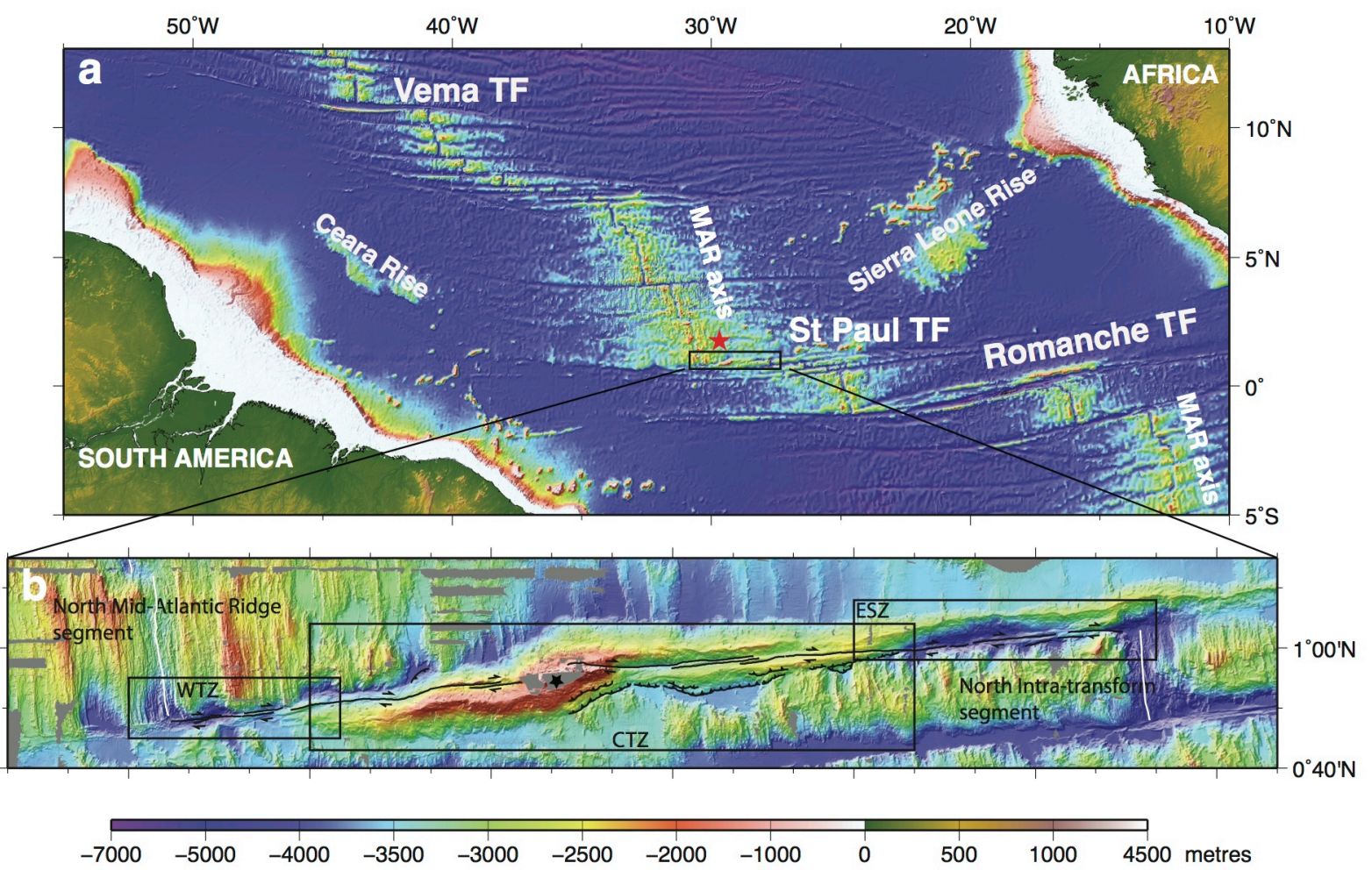
WTZ

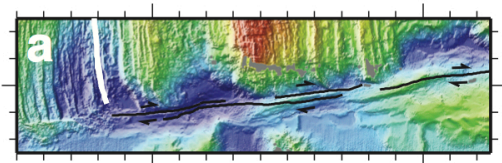

$30^{\circ} 20^{\prime} \mathrm{W}$

CTZ

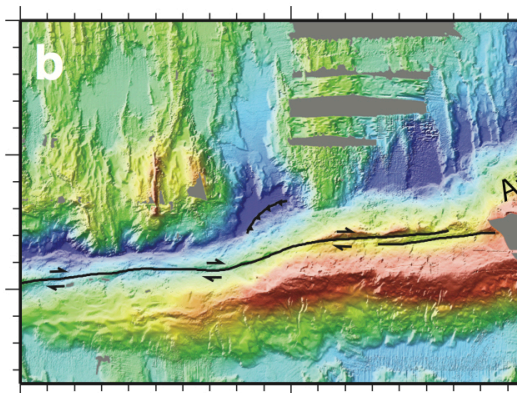

$30^{\circ} 00^{\prime} \mathrm{W}$ $0^{\circ} 50 ' \mathrm{~N}$

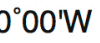

ESZ

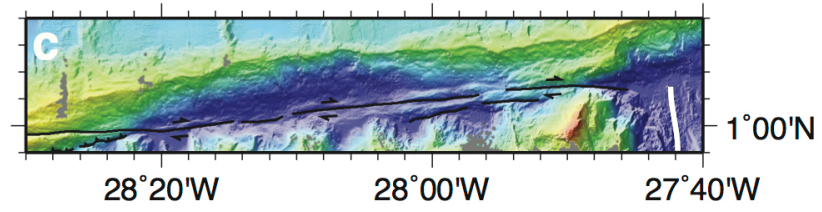

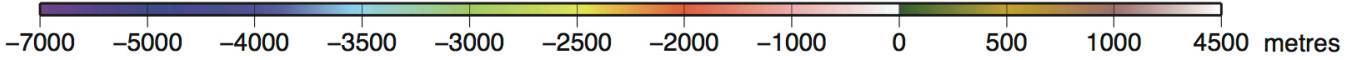




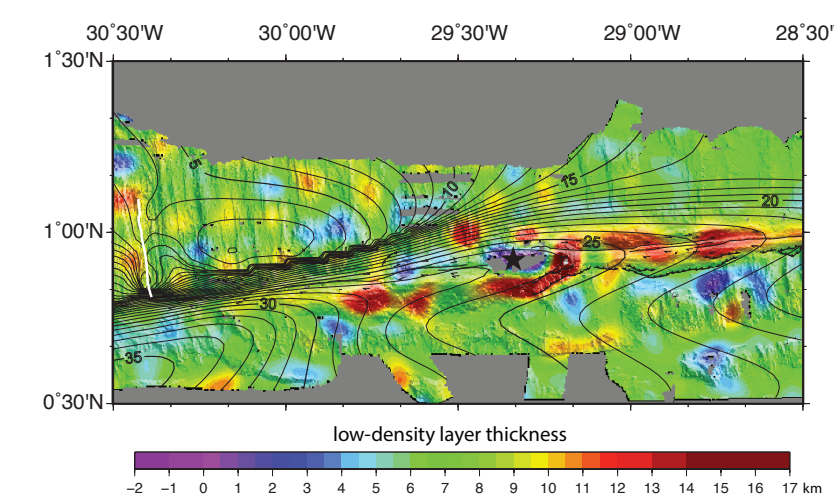


prior to the $5^{\circ}$ counterclockwise

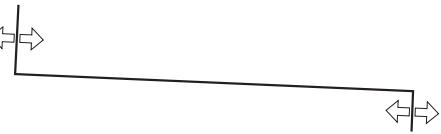

change in the spreading geometry ural ridge 11-10 Ma

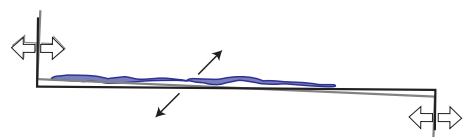

first southward propagation

compressional growth of the

flexural ridge
$10-8 \mathrm{Ma}$

second propagation step

push-up ridge

8-5 Ma
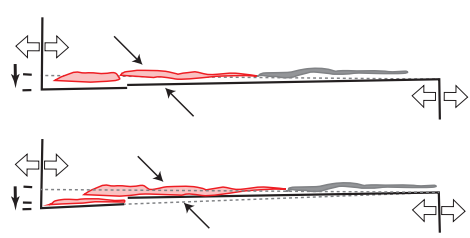

third propagation step growth of the push-up ridge formation of the graben

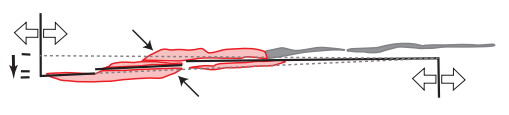

present day propagation growth of the push-up ridge en-echelon small pressure ridges

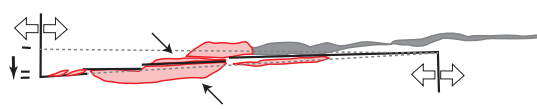

